\section{Uma teoria crítica dos novos meios de comunicação}

RESUMO

Neste ensaio destacam-se não só as idéias do sociólogo francês Dominique Wolton sobre a Internet, os meios de comunicação de massa e a sociedade, expressas em Internet, e depois? Uma teoria crítica dos novos meios de comunicação, mas também alguns aspectos contraditórios de seu texto.

\section{ABSTRACT}

In this essay the author points out some contradictions of Dominique Wolton in his last book about the Internet, society and mass communication.

PALAVRAS-CHAVE (KEY WORDS)

- Comunicação (Human communications)

- Sociedade (Society)

- Novas tecnologias (New technologies)

\section{Sandra Montardo}

Doutoranda do PPGCom da FAMECOS/PUCRS
Pensar a transformação das implicações da comunicação na sociedade, levando em conta o desenvolvimento dos novos meios de comunicação, é a proposta de Dominique Wolton em Internet, e depois? - Uma teoria crítica dos novos meios de comunicação (Barcelona, Gedisa Editorial, 2000). O debate sobre os principais tópicos referentes a essa questão foi proposto pelo autor no seminário Internet, e depois?, proporcionado pelo Programa de Pósgraduação em Comunicação Social da PUC-RS, entre 01 e 04 de outubro de 2001. Este ensaio tem por objetivo explicitar estes tópicos, comentando-os sempre que parecer necessário.

Já na introdução de seu livro, Wolton classifica a época atual como "uma nova era da comunicação", tendo em vista o advento da informática e dos sistemas multimídia. Com isso, o autor alerta para o que considera o maior perigo dessa nova era: a dimensão técnica da comunicação substituir sua dimensão humana e social. Assim, a comunicação, centro da experiência individual e social, teria evoluído em duas direções: a das técnicas e a dos valores da sociedade democrática. Desde já, cabe perguntar até que ponto a técnica e os valores da sociedade democrática excluem-se entre si. Ou, então, perguntar pelo indicativo de que ambos os tópicos não se refiram ao mesmo fenômeno.

Para o autor, a comunicação combina tanto a luta pelos ideais de liberdade e a democracia quanto os interesses e os benefícios de uma lógica comercial, principalmente com as novas tecnologias. $O$ interesse investigativo da comunicação reside, justamente, na mescla dessas dimensões.

Quanto a esse ponto, cabe aprofundar a questão posta anteriormente. Não 
teria sido justamente o ambiente social propício para o desenvolvimento da democracia o mesmo do qual se valeu a lógica comercial para se colocar? E, ainda, o aperfeiçoamento das tecnologias de maneira geral não teria acompanhado esse mesmo processo?

O papel da comunicação na questão da emancipação do indivíduo e o surgimento da democracia a colocam no centro da modernidade. Assim, Wolton aponta para a fundamentalidade da comunicação, atualmente, pelas seguintes razões: pressupõe a existência de seres livres para os quais a liberdade de comunicação e de informação constitui a égide de todas as relações sociais e políticas, deve gerir os movimentos contraditórios entre a liberdade individual e a igualdade de todos, além de também ser a condição necessária para que haja a democracia de massas.

Partindo desse ponto de vista, o livro pretende distinguir a lógica dos interesses (comerciais) da lógica dos valores (democráticos) na questão da comunicação nessa nova era, considerando hipóteses precisas. Isso no sentido de diferenciar normas de interesses, frente ao posicionamento de atores políticos e industriais, em uma época de instrumentalização da comunicação, através de novas técnicas produtivas e da abertura de mercados importantes. Com relação a esse ponto, a comunicação também deve gerenciar as diferenças entre as sociedades, as quais são destacadas em um mundo de tecnologias da informação onipresentes. Frente a isso, o objetivo deste livro é compreender a força com a qual a ideologia técnica irrompe na comunicação, a partir do questionamento sobre o "futuro da internet" e a "guerra dos meios de comunicação". E isso em termos de verificar possíveis rupturas na economia da comunicação com o surgimento da internet e também relacionar a revolução tecnológica com alterações de conteúdo observada com outras inovações técnicas significativas na história da comunicação.
Além disso, o autor promete contrapor a internet e televisão sob vários aspectos.

Para acentuar o seu posicionamento crítico frente às novas tecnologias, Wolton deixa clara a sua intenção de diferenciar o seu discurso do discurso dos empresários, dos jornalistas e dos políticos, os quais endossariam facilmente a lógica dos interesses comerciais da comunicação. E isso porque investigar significa ir além do que é visível e evidente. $O$ que em ciências sociais significa introduzir uma nova lógica à preponderante. No caso do livro em questão, trata-se de investigar a existência de uma ruptura efetiva em termos de uma teoria da comunicação, entre os meios de comunicação e as novas tecnologias, bem como verificar uma mudança substancial na economia da comunicação.

Nesse momento do livro, o autor apressa-se em se colocar favoravelmente às novas tecnologias. Afinal, um dos maiores objetivos do livro, segundo o seu autor, é justamente destacar a importância do posicionamento crítico frente às novas tecnologias de comunicação, o que não significaria, necessariamente, negá-las. Esse comentário parece, no mínimo, descartável e, no limite, estranho. A pergunta que fica aqui é: para quem o autor dirige este comentário?

Para entender o papel da comunicação na sociedade, Wolton sugere que se analise as relações entre os três aspectos fundamentais da comunicação: o sistema técnico, o modelo cultural dominante e o projeto social. Por mais espetacular que tenha sido o avanço das tecnologias de comunicação, desde $O$ surgimento da imprensa, no século XV, até o dia de hoje, o autor salienta que não se deve reduzir a compreensão da comunicação de uma época à produção de tecnologias contemporâneas nessa área.

Afinal, para o autor, não são os resultados técnicos que interessam ao estudo da comunicação. Sua importância está em verificar, por exemplo, as seguintes questões: se existe mesmo uma mudança 
real entre os meios de comunicação de massas e a internet; se a inovação das novas tecnologias está relacionada com uma mudança nos modelos de comunicação individuais e coletivos; se existe, frente a essas inovações, outro projeto de organização da comunicação, assim como o de outro papel de sua organização em uma sociedade aberta.

A teoria do determinismo tecnológico, que vem se confundindo com uma ideologia técnica da comunicação é, dessa maneira, descartada por Wolton. Ao contrário, o autor pretende explicar por que o essencial em um sistema de comunicação não é a técnica. Vale lembrar, aqui, que o autor considera que não há uma teoria da comunicação sem uma teoria implícita ou explícita da sociedade. Ainda o autor afirma que o objetivo das novas técnicas de comunicação é separar a comunicação do problema da produtividade.

Os três objetivos visados pelo autor neste livro são: contribuir para uma revalorização teórica da comunicação, tratando-a como um valor essencial do nosso patrimônio cultural e não somente como uma questão tecnológica ou de mercado; defender uma reflexão sobre a televisão, devido ao seu papel central em uma teoria da comunicação na democracia de massas; e, finalmente, tocar o sinal de alarme para a Europa, no sentido de que este continente tem todas as condições para tomar atitudes críticas frente às novas tecnologias mas, assim mesmo, não se diferencia da visão norte-americana sobre o tema, ao adotar o discurso ideológico de se tornar "a primeira sociedade da informação e da comunicação" a qualquer custo.

Já quanto aos dois objetivos teóricos, Wolton destaca o de restabelecer o vínculo entre teoria da comunicação e teoria da sociedade, bem como o de reavaliar a problemática das massas e da quantidade. $O$ primeiro desses objetivos diz respeito ao receptor, no sentido de que este é freqüentemente considerado como manipulável pelos meios de comunicação, ao mesmo tempo que não o é pelas mensagens políticas.

Assim, trata-se também de reconhecer a comunicação como uma grande questão teórica da democracia.

Da mesma forma, o segundo objetivo é insuficientemente assistido pela teoria, tendo relação direta com uma teoria da comunicação e, logo, da sociedade, já que se relaciona com comunicação de massa e com democracia. O autor ainda realça que estes dois objetivos têm a ver não só com a dimensão tecnológica da comunicação, mas também com as dimensões cultural e social.

Ao final desse capítulo de introdução, vale ressaltar algumas dúvidas que o mesmo suscita e que acompanharão todo o texto do livro. Em primeiro lugar, ao que parece, os "três objetivos" (WOLTON, 2000, p.20, trad. por Sandra Portella Montardo) a serem perseguidos pelo autor, postos antes dos "dois objetivos teóricos" (WOLTON, 2000, p.24, trad. por Sandra Portella Montardo) descritos anteriormente, são igualmente teóricos. Afinal, o que não seria teórico em um livro que se destina a destacar a importância de um posicionamento crítico frente às novas tecnologias da comunicação?

Mais uma vez, parece necessário perguntar-se para quem é endereçado este livro. Para os estudiosos na área, para os políticos, para os jornalistas, para os industriários, para quem utiliza os meios de comunicação, sejam eles de massa ou não? Trata-se de um documento pela defesa de um sistema de regulamentação dos meios de comunicação e das novas tecnologias de comunicação? Ou de um manual a ser destinado para o grande público, mostrando-lhe a postura correta frente às novas tecnologias da comunicação?

O mesmo acontece com a palavra comunicação. Ainda que este capítulo de introdução sugira que comunicação tem a ver com um conceito sociológico que combina a dimensão técnica, um projeto 
social e um modelo cultural, algumas vezes esse termo é reduzido apenas como uma dessas dimensões. O primeiro parágrafo do próximo capítulo demonstra esse ponto. Além disso, o texto também é obscuro quanto à utilização do termo "novas tecnologias da comunicação", conforme veremos adiante.

Com certeza, o esclarecimento dessas questões facilitariam o entendimento de alguns termos utilizados, ampliando a compreensão da obra como um todo. Ainda que para isso, talvez, fosse necessário reduzir o espectro de abrangência do mesmo. Pois, por exemplo, alguns conceitos parecem referir-se a questões diferentes em momentos diferentes do livro. Ocorre, dessa maneira, uma dispersão acerca de assuntos relevantes para a nossa época, com relação aos quais Wolton demonstra apurada sensibilidade.

\section{A comunicação no centro da modernidade}

Da invenção do telefone à da informática, a comunicação tecnológica tem cerca de um século, sendo, atualmente, um setor vital nas sociedades contemporâneas. Para o autor, a grande diferença entre a comunicação do século $\mathrm{XX}$, que é capaz de transmitir som e imagem, e a da imprensa é a de ter atingido todos os públicos. Com isso, essa comunicação atingiu todos os meios sociais e culturais.

Considerando como símbolo da sociedade atual o tríptico sociedade de consumo, democracia de massas e meios de comunicação de massas, Wolton admira-se ao afirmar que se tem pensado pouco a respeito da quantidade e das massas. Daí a importância de incluir a questão das novas tecnologias em uma teoria geral da comunicação e dos meios de comunicação de massa, para que se entenda seus limites e interesses. Até porque o autor admite, em uma mesma ordem cultural, o grande público dos meios de comunicação de massas e o sufrágio universal na política.

$\mathrm{Na}$ recente história da comunicação, Wolton destaca duas revoluções: a dos meios de comunicação de massa e a das novas tecnologias de comunicação, a multimídia. Enquanto a primeira atingiu o grande público, esta última individualiza cada vez mais o seu acesso. Ao mesmo tempo que admite que a comunicação está em constante mudança, há um século, o autor aponta para um "pacto" feito com as tecnologias e com a técnica que parece obrigar a todos a entrarem em um ritmo trepidante.

Vale notar, no entanto, que esse "pacto" com a técnica deve ser o mesmo que deu origem ao aparecimento dos meios de comunicação de massa. E se "pacto" faz referência a duas partes interessadas, uma dela é o público, ou melhor, o usuário dessas novas tecnologias individualizantes. A outra, Martin Heiddeger, ao pensar a questão da técnica, parece ter se arrependido de tentar nomear.

Segundo Wolton, a "história da comunicação é tão antiga quanto a do homem" (Wolton, 2000, p.36, trad. por Sandra Portella Montardo), enquanto a das tecnologias é mais recente. Dada a facilidade de adaptação dos homens às novas tecnologias, que deve acelerar-se ainda mais, o autor estranha a falta de discussões e mesmo de controvérsias a respeito. $E$ isso porque, para ele, criticar as novas tecnologias soa como uma afronta ao progresso.

Mais uma vez, surge a dúvida quanto à utilização do termo comunicação. Que tipo de história da comunicação é tão antiga quanto a do homem? Se o homem é pré-histórico e a história teria surgido com o aparecimento da escrita, do que o autor estaria falando? Afinal, comunicação, para ele, não teria a ver com a dimensão técnica, com projeto social e com um modelo cultural? Não seria uma questão que está no centro da modernidade, conforme o título do capítulo indica? 
A tendência em identificar a "sociedade do amanhã" com a "sociedade da informação ou da comunicação" reflete a tendência de reduzir-se comunicação à tecnologia. Quanto a isso, Wolton ressalta sua hipótese de que uma tecnologia de comunicação só ocupa lugar central em uma sociedade "porque simboliza, ou catalisa, uma ruptura radical que existe simultaneamente na cultura dessa sociedade" (WOLTON, 2000, p. 38, trad. por Sandra Portella Montardo).

O autor francês ainda atribui à falta de reflexão sobre a televisão, os meios de comunicação e as novas tecnologias, a continuidade das inovações tecnológicas. Com a evidência da falta de reflexão sobre a comunicação, Wolton associa o fato de que esta tenha se tornado interessante para a ideologia da tecnologia e a de mercado. Ou seja, se as tecnologias de comunicação são destaque desta última, sua essência é o modelo cultural que transportam, o projeto relacionado com este, e, assim, a organização do sistema de comunicação de uma sociedade.

O resultado deste quadro, para ele, é a entrada do setor privado nas telecomunicações, os canais temáticos, a televisão a cabo e a desregulamentação. Frente a isso, o autor chega a afirmar que, em comunicação, é a técnica que define o conteúdo. Uma afirmação assim demandaria delimitação, contextualização e, até mesmo, demonstração, dado o contrato que o autor faz com o leitor de basear-se em hipóteses claras e precisas ao escrever o livro. Com isso, o autor reitera a pertinência em se perguntar pela posição da comunicação na cultura ocidental.

Com relação ao já consagrado desinteresse teórico a respeito da comunicação, Wolton ressalta o paradoxo da comunicação: ao lado dos conceitos de liberdade, igualdade e fraternidade, no plano da política, está a comunicação. No entanto, esta nunca adquiriu legitimidade, antes sendo identificada com transferência de influência e de manipulação. Para que o entendimento fosse facilitado, caberia colocar quando e por quem exatamente a comunicação tem sido identificada como influenciadora e como manipuladora.

O autor organiza esta desconfiança quanto à comunicação em quatro momentos, os quais distribuem e sugerem mais referências ao conceito de comunicação. O primeiro relaciona-se com o descarte de atenção teórica sobre a comunicação em escala individual. Esta teria sido sinônimo de qualquer experiência humana, da possibilidade de contato do homem com o próximo e com o mundo. Afinal, a comunicação começou a ser estudada há apenas um século, aproximadamente, tendo sido identificada com o movimento de liberação do indivíduo. O que todavia não veio a significar a sua valorização efetiva, provavelmente, no plano teórico.

Já a comunicação em grande escala, a partir da comunicação interpessoal, tem como marco da desconfiança a tentativa de manipulação e a influência de modo geral. Relaciona-se com a luta pela democracia e coincide com o aparecimento da imprensa. Num terceiro momento, tem-se os meios de comunicação de massas, principalmente rádio e televisão, no que se referem ao medo da manipulação e à desconfiança quanto à quantidade.

O quarto momento seria o do surgimento das novas tecnologias, representando, mais uma vez, para muitos, a solução para os problemas de comunicação interpessoais, acentuando a individualização do acesso às suas ferramentas.

Tem-se, então, que o objetivo continua sendo o de mediatizar a comunicação, que é sempre ambígua, no plano da experiência, com conhecimentos. O que significa diferenciar comunicação normativa da comunicação funcional, separar as promessas e a realidade, bem como o irreal da comunicação e suas promessas. Tratase, enfim, de investigar a comunicação 
como questão de valor na questão das quantidades em sociedades abertas. Para entender, assim, que comunicar mais e mais rapidamente não significa comunicar melhor.

Outro fator que colabora com a alegada desconfiança frente à comunicação é a posição da imagem. Os trabalhos teóricos sobre a imagem, da semiologia à antropologia cultural, nos últimos cinqüenta anos, parecem não ter sido suficientes para aproximar as reações contrastadas que esta suscita. Ou seja, a de paixão desenfreada, pelos fabricantes de imagem, e a desconfiança das elites. Como se não tivesse ficado claro, por meio destes estudos, que da imagem, que é heterogênea, extrai-se muitos significados.

Em tempo, pergunta-se se o autor fala em elite econômica, cultural, intelectual ou todas ao mesmo tempo. $\mathrm{E}$ ainda, que independente de qual dessas elites se trate, elas também devem ser apaixonadas pelas imagens. Afinal, os canais temáticos, bem como as demais tecnologias acessíveis individualmente, são dirigidos, mercadologi camente, para elas.

Para construir a distância teórica entre o objeto, a imagem e a análise, Wolton sugere a observação dos quatro seguintes fenômenos: valorizar o contexto histórico, reconhecer a dimensão crítica do receptor, compreender que a imagem não é única e, finalmente, entender que sem imaginação não há imagem. Em resumo, assim como em qualquer outro processo comunicativo, o indivíduo é livre para interpretar a imagem, na medida em que diversos fatores estão interligados.

No entanto, com o advento das novas tecnologias de comunicação, Wolton alerta para um perigo com relação à imagem. O autor sustenta que deve haver uma carta de regulamentação internacional que diferencie o que é realidade do que é realidade virtual. Isso em todas as etapas de produção da imagem, da difusão até a recepção, sob o risco de obter-se conseqüências culturais e políticas graves.
Aqui, Wolton identifica mais um paradoxo: o do silêncio teórico frente à questão da realidade e da realidade virtual, uma das questões mais ruidosas concernentes às novas tecnologias de comunicação. Deve-se pontuar, entretanto, que essa questão deve ser contemporânea desde o surgimento da imprensa, sendo que o público desde então lida com essa possibilidade. O que garantiria, além disso, que, principalmente na nossa época, o virtual não seria, democraticamente, mais interessante para esse público?

Em seguida, Wolton relativiza o silêncio teórico sobre a comunicação, tendo em vista a falta de demanda pelos muitos livros e artigos já publicados a respeito. Em contraponto, o autor situa os inúmeros discursos que exaltam as novas tecnologias de maneira acrítica. De advogados, juízes, passando por técnicos, engenheiros, publicitários, estrelas da televisão, especialistas em audiência, jornalistas e empresários, o autor ouve discursos muito próximos. Entre os quais, os que oscilam entre a defesa do setor privado de comunicação, bem como da continuidade da desregulamentação desta, assim como as duras críticas aos meios de comunicação de massas, acompanhadas pela celebração à individualidade e à interatividade de acesso às novas tecnologias.

Este não é o único capítulo em que Wolton falará da necessidade do fim da desregulamentação em comunicação. No entanto, é válido o questionamento que percebe a possibilidade de que os interesses comerciais, na visão do autor, respaldados pela técnica, continuem a estabelecer os critérios no caso de uma regulamentação do setor.

Para finalizar, o autor observa três características da comunicação que fazem alusão ao contra-senso do qual foi objeto primeiramente a televisão e, hoje, as novas tecnologias de comunicação. Pode-se observar, aqui, um curioso desmembramento da dimensão técnica 
da comunicação com relação ao projeto social e ao modelo cultural, aos quais a comunicação também se refere.

Assim, tem-se que, da mesma maneira que a comunicação, a televisão nunca obteve legitimidade cultural nem intelectual. Por outro lado, percebe-se que as práticas, em comunicação, mudam menos rapidamente que os discursos. Afinal, o número de usuários da internet é inexpressivo frente ao dos meios de comunicação de massa, apesar do incentivo constante. Finalmente, o autor reitera a idéia de pensar a comunicação em termos da proposição de um modelo de comunicação que contemple uma sociedade aberta com o problema das identidades debilitadas. Uma reflexão sobre essa questão é posta no próximo capítulo.

2 - Meios de comunicação geralistas e grande público

A televisão geralista é um sucesso popular. Por outro lado, não tem nenhuma legitimidade cultural, nem intelectual, junto às elites culturais. $E$ isso devido ao fantasma da manipulação, bem como o de baixar o nível cultural pela programação. Elites estas que sempre lutaram pela democracia, sem se dar conta de que a televisão correspondia, em parte, ao ideal democrático. Isso na medida em que permite 0 acesso de grande quantidade de público à informação, à cultura e à informação.

O sucesso da televisão pode ser também percebido com os avanços surgidos com as novas tecnologias. Os aparecimentos do cabo e, mais tarde, dos canais temáticos dividem o público em três partes desiguais: o maior para a TV geralista, o intermediário para serviços de cabo e um ainda menor para os serviços multimídia.

$O$ autor ainda identifica o duplo movimento de uso da programação da televisão e decepção com a mesma, simultaneamente, com a liberdade crítica da recepção junto a sua deslegitimidade. Liberdade crítica esta apontada por Wolton, que contraria os fundamentos das teorias comunicativas que alegam a manipulação dos emissores sobre os receptores do processo de comunicação. Afinal, "olhar não significa obrigatoriamente aderir ao que se olha" (Wolton, 2000, p. 70, trad. por Sandra Portella Montardo).

Nesse sentido, Wolton faz um elogio da banalidade quanto ao uso da televisão. $E$ isso no sentido de que esta assuma o papel de abrir ao mundo, tanto a experiência pessoal como o acesso à história. No entanto, esta abertura ao mundo, se dá pelo espetáculo, não devendo ser a televisão uma escola de imagens.

A distância tomada pelas elites culturais e intelectuais da televisão demonstrar, para o autor, a dificuldade em compreender os três grandes problemas da modernidade. Problemas que são: a comunicação, a quantidade e a relação entre esfera privada e esfera pública em uma sociedade aberta.

Ligada a essa falta de reflexão sobre a televisão está a dificuldade em se pensar a sociedade contemporânea, diz o autor. E, por conseqüência, entender que em duas gerações passou-se de duas culturas, a de elite e a de massas, para quatro formas de cultura: a cultura de elite, a mediana, a de massas e a particular.

Pode-se dizer que há, realmente, uma ligação entre a dificuldade em se pensar a sociedade moderna e, com isso, as tecnologias produzidas pela mesma. Muitos pensadores, ao abordar essa questão, a começar por Friedrich Nietzsche, de uma forma ou de outra, apontaram para a fragmentação do indivíduo, da cultura, da vida como fatores relacionados a tal dificuldade. O mais curioso é que o autor, logo em seguida, faz menção à fragmentação. Isso ao tornar identificável quatro tipos de cultura.

Evocar a questão da televisão geralista é cada vez mais difícil sem haver o contraponto com a televisão temática. Esse contraponto, por sua vez, traz à tona 
aspectos referentes à lógica da oferta e à lógica da demanda. Ao contrário dos discursos correntes, Wolton considera mais importante ampliar a oferta e a qualidade da programação da televisão geralista para que se constitua marcos de compreensão do mundo sobre os quais a demanda possa se manifestar.

Por outras palavras, a lógica da demanda, que também se relaciona com o acesso à internet, opõe-se diretamente à da oferta. E isso porque uma demanda segmentada, cada vez mais, tem significado um número maior de consumidores, o que vem a contentar o mercado crescente dos produtos e serviços tecnológicos da comunicação.

É justamente por pensar que uma teoria do público pressupõe uma teoria da televisão e, em seguida, uma representação da sociedade, que Wolton alerta para o papel social da televisão geralista. A esta caberia, também, a prestação de serviços públicos e da manutenção, ou até mesmo, do reforço das identidades nacionais. A inscrição da televisão no setor privado, que é orientado pela audiência e pelos investimentos publicitários, ameaça esse papel social da televisão.

No entanto, é interessante para os anunciantes que haja audiência para os programas televisivos a serem patrocinados ou pela faixa de horário que se deseja anunciar. Pode-se dizer, então, que audiência significa pessoas que se identificam com um determinado tipo de programação.

Ou, por outras palavras, com uma determinada estética, com uma determinada visão de mundo veiculada. O que, de um jeito ou de outro, faz sentido quando se fala em assegurar uma identidade nacional, segundo a lógica do autor.

Outro aspecto interessante da televisão geralista é a sua capacidade de demonstrar as dificuldades da comunicação. Isso, principalmente, por tornar constatável as diferenças entre as lógicas do emissor, da mensagem e do receptor. Já a racionalidade e a eficácia da televisão temática não possibilitam esta constatação, ainda que sejam necessárias as suas existências a título de contraponto.

Ainda segundo o autor, privilegiar uma concepção de grande público da televisão é inscrevê-la na questão da democracia. $\mathrm{E}$ também identificar esse público com - sufrágio universal na política. Ou seja, todo o julgamento de indivíduo passível de manipulação pela televisão conferido ao telespectador deve ser estendido ao cidadão que, por sua vez, escolhe os seus representantes na sociedade. Quanto a esse ponto, caberia investigar mais a fundo se a questão da quantidade ligada ao conceito de democracia não suscitou, em algum momento, a mesma impressão que o conceito de grande público suscita hoje para o meio intelectualizado.

Por fim, o autor também atribui à televisão geralista o objetivo essencial do "estar juntos de uma coletividade", ao contrário da interatividade individualista das novas tecnologias da comunicação. Com isso, o autor afirma que a televisão serve para reunir indivíduos e públicos que em situações sociais normais estariam separados, oferecendo-lhes, com isso, a possibilidade de participar individualmente em uma atividade coletiva. O que faz da televisão um instrumento de conversação.

Para finalizar, o capítulo sobre os meios de comunicação de massa e grande público destaca um manifesto redigido pelo autor a respeito do papel da televisão geralista hoje, contando, também, com alguns alertas para o futuro. Estes pontos orientaram o Comitê Francês de Audiovisuais, criado em 1993, com o objetivo de defender a televisão geralista pública.

Nesse manifesto, Wolton destaca a responsabilidade de quem dirige e produz para televisão, dado o seu papel social e cultural, além da importância da regulamentação do setor audiovisual devido à abundância das imagens. O autor defende o equilíbrio entre setor privado 
e público em televisão, sendo que em um ou outro sistema deve prevalecer, em termos de audiência, o modelo geralista de televisão. Assim, caberia aos canais temáticos complementar a programação dos canais geralistas. Em todos os aspectos relativos à televisão, Wolton destaca a influência da ideologia da técnica e do mercado.

Vale ressaltar que algumas dessas medidas parecem pouco democráticas, um valor defendido pelo autor. Determinar que a audiência de um tipo de televisão deva prevalecer sobre o outro parece problemático nesse sentido. No entanto, a influência do que o autor denomina a ideologia da técnica e a de mercado sobre o setor audiovisual encarrega-se disso. Isso, na medida em que os canais temáticos atingem e deverão continuar atingindo uma parcela significativamente menor do que a audiência da televisão geralista.

2 As novas tecnologias, o indivíduo e a sociedade

Pode-se dizer que este capítulo destina-se a relativizar a importância e o alcance das novas tecnologias de comunicação, no sentido de apontar suas limitações e seus interesses. Num primeiro momento, o autor aborda os triunfos das novas tecnologias de comunicação.

Assim, o autor começa por situar as novas tecnologias de comunicação em uma lógica da demanda, ao contrário da televisão, do rádio e da imprensa, que se orientam por uma lógica da oferta. Em seguida, o autor observa que, ainda que não haja uma hierarquia entre os meios de comunicação de massa e as novas tecnologias da comunicação, tampouco há uma equivalência entre ambos.

Mais uma vez, Wolton critica os discursos dos políticos, dos meios de comunicação e das elites relativos às novas tecnologias de comunicação. Principalmente pela exaltação que o autor julga apressada dessas novas tecnologias, como se fossem o sinônimo de progresso e de desenvolvimento da "sociedade do amanhã". No entanto, Wolton vale-se de antigas promessas tecnológicas para demonstrar que a sociedade muda menos que os discursos sobre ela.

Ao invés dos termos "mudança", "transformação", "revolução" das novas tecnologias, o autor associa a essa questão o termo de transferência. Ou seja, existem atualmente novos suportes técnicos para que se trate de símbolos e utopias que sempre fizeram parte da vida social. O fato de que internet signifique autonomia, organização e velocidade é o que alimenta a idéia de um espaço transparente, sem hierarquias ou exigência de competência. Assim, a internet torna-se a figura de uma sociedade onde os homens são livres para emancipar-se a si próprios.

As novas tecnologias da comunicação, entre as quais tem destaque a internet, na verdade, exigem competência para a seleção das informações que dispõem, correspondem a uma necessidade de atuar dos indivíduos, além de animar a capacidade de criação. Quanto a este último aspecto, a rede lança a busca por estilos e formas que expressam a modernidade. Por outro lado, a rede alimenta a utopia de uma nova solidariedade mundial, dizendo respeito à ecologia, por exemplo. Ou seja, a rede é também um suporte para quem deseja construir um mundo melhor, mostrando que sociedade global possa não se relacionar somente com globalização econômica.

Ao falar sobre o conteúdo da internet (a rede, Usenet, o IRC, o FTP, etc.), Wolton esclarece o serviço que se destaca junto ao grande público é a rede. A partir dessa discriminação, surgem algumas dúvidas quanto à pertinência de utilizarse rede e internet como sinônimos. No entanto, isso acontece. Entre a oferta organizada de serviços disponíveis pela rede estão: aplicações de informações e de serviços de utilidade pública, aplicações do tipo ócio (jogos interativos em rede 
e vídeos), informações-acontecimento (disponibilizados por agências de notícias e por jornais e por profissionais especializados) e informaçõesconhecimento (bancos de dados acessíveis por meio de pagamento).

O sucesso da rede deve-se ao fato de que o campo da informação se amplia cada vez mais, diversificando-se e integrandose a novas dimensões. Junto a isso, os provedores potenciais são numerosos e competem por novos mercados. Podese notar que o problema da rede não é a crescente oferta de informações, mas a criação da obrigação de estar bem informado vinte e quatro horas por dia.

Dito isto, fica claro que, na rede, a oferta supera a demanda do grande público. E, já que se conhece pouco das necessidades da demanda, a organização da oferta pode ser observada quanto à natureza dos serviços oferecidos. Por outras palavras, observando-se uma lógica técnica, por parte das aplicações, e uma lógica social, que visa a dar conta das supostas necessidades dessa demanda.

Provavelmente, Wolton sugeriu essa chave de análise sobre a oferta de informações pela rede por ter constatado a falta de vínculo entre os quatro tipos de serviços mencionados. Nessa falta de vínculo, Wolton identifica, também, a falta de uma unidade teórica.

Contrapondo os meios de comunicação de massa e a rede, o autor associa o ideal democrático aos primeiros. $\mathrm{E}$ isso porque, desde o século XVIII, a informação insere-se em um contexto que leva em conta o indivíduo e a democracia. Assim, em nome da igualdade e da liberdade, a informação deve divulgar a realidade, chamando 0 indivíduo à atuação. Vale a pergunta que busca pela recepção da imprensa dessa época. Por outras palavras, qual era o percentual de alfabetizados entre a população das cidades que testemunharam o nascimento da imprensa? E, também, a que conceito de igualdade fazia referência a imprensa?
Já sobre a informação disponibilizada pela rede, Wolton identifica o reaparecimento da desigualdade. Seja social, pela segmentação dos conteúdos especializados, seja pelo dinheiro que se deve dispor para que se acesse muitas dessas informações. Já aqui, uma outra interpretação é possível. Por exemplo, o percentual de pessoas que têm acesso às informações especializadas disponibilizadas pelas novas tecnologias de comunicação, número provavelmente próximo ao do percentual de alfabetizados no século XVIII, são tão ou mais livres do que os leitores da imprensa em sua origem, conforme a lógica do autor. A questão do conceito de igualdade continua em suspenso.

Frente à concentração das atividades que antes eram possibilitadas por terminais diferentes (televisão, rádio, telefone, imprensa, etc.) apenas no computador, o autor comenta as diferenças existentes entre meios de comunicação de massa e a rede.

Quanto aos meios de comunicação de massa, Wolton observa o vínculo que deve existir necessariamente entre emissor, mensagem e receptor. Desse modo, há a pressuposição de que cada meio de comunicação de massa esteja vinculado a uma comunidade de língua, de valores e de referências. Com o que se torna necessária a reflexão sobre a demanda e o público ao qual se destina. Além disso, os meios de comunicação de massa promovem a relação entre a escala individual e a escala coletiva.

Já quanto à rede, esta se resume, em grande medida, a um sistema de transmissão e de acesso a um gigantesco número de informações. Por ter abrangência mundial e usuários com potencial de assim sê-lo e, ainda, por ser orientada por uma lógica da demanda, a rede deixa de ser caracterizada como meio de comunicação de massa. Enquanto identifica os meios de comunicação de massa com uma preocupação acerca da melhora das relações interpessoais, 
Wolton liga a rede mais a um interesse de desenvolver a economia-mundo.

Pensar a relação do indivíduo frente aos novos meios de comunicação é darse conta, basicamente, de que as novas tecnologias de comunicação não resolvem o problema da comunicação. Como exemplo, Wolton cita as solidões interativas proporcionadas pela rede, que em nada garantem uma boa comunicação com o próximo.

Também a questão do tempo é tocada no que tange à falta de relação entre o presente eterno das novas tecnologias e a experiência humana. Já a transparência das relações que supostamente seriam mais diretas, revela uma série de filtros, proibições ou signos de distinção para proteção das relações no ciberespaço. No entanto, o perigo maior é uma provável vitória total da racionalidade dos sistemas técnicos que aniquilassem o ruído da comunicação. Aqui sim ter-se-ia uma substituição da comunicação pela informação, com todos os danos possíveis.

Outro ponto ressaltado por Wolton é o da relação dos novos meios de comunicação entre comércio e democracia. O autor começa falando que a questão do número sempre incomodou quando relacionado com os meios de comunicação de massa. No entanto, é motivo de festa quando se refere ao número de usuários da rede.

Para Wolton, pensar em grande público dos meios de comunicação requer recorrer a uma teoria da cultura, que se analise a relação entre política e cultura no seio da democracia de massas. Isso tudo para que não se reduza a questão do grande público ao número de consumidores, como acontece com os usuários da rede, segundo Wolton.

O autor também critica a falta de regulamentação das informações que abastecem a rede, situação que instala uma constante insegurança quanto à veracidade das mesmas. Wolton defende o controle da informação como sendo o único modo de salvar a rede, já que não vê relação imediata entre acesso direto à informação e democracia. Como solução desse quadro, o autor sugere a intervenção de intermediários de qualidade que verificassem as informações que circulam pela rede, bem como a sua utilização.

Pelo contrário, ao perceber a indistinção entre consumidores e cidadãos na internet, o autor alerta para a incompatibilidade entre a lógica comercial e os direitos do homem. Assim, cada vez mais deve ser levada em conta a defesa da comunicação normativa frente à comunicação funcional, tão em moda com as novas tecnologias de comunicação. No entanto, vale destacar que uma regulamentação da internet que significasse segurança total quanto à veracidade das informações talvez a identificasse ainda mais com uma comunicação funcional, criticada pelo autor.

Escapar para a guerra dos meios de comunicação

Visando a descartar o desvio da discussão sobre meios de comunicação de massa e novas tecnologias de comunicação para velhas problemáticas, Wolton propõe duas premissas para o tratamento do tema. A primeira seria a de evitar a definição tecnológica de comunicação, privilegiando a definição que a contempla como combinação entre as dimensões tecnológicas, sociais e culturais. A segunda declara que não há oposição entre os meios de comunicação de massa e entre as novas tecnologias de comunicação, já que ambos os tipos de suportes técnicos lidam com a relação contraditória entre escala individual e a escala coletiva. Os primeiros dirigindo-se ao grande público e as últimas, para o acesso individual.

Entre os objetivos comuns aos meios de comunicação de massa e às novas tecnologias de comunicação está a necessidade de reflexão sobre a 
comunicação, valorizando a importância da regulamentação da mesma. Para o autor, a desregulamentação do setor pode significar a regulamentação do mesmo pelo mercado. No entanto, nada assegura que o mesmo aconteça em nome de uma regulamentação do setor.

Nesses termos, observa-se também a questão da relação entre a comunicação funcional, que diz respeito à estandartização das aplicações tecnológicas pelo mundo, e a comunicação normativa, que concerne à preservação das identidades culturais. Segundo Wolton, deve-se evitar que a mundialização da comunicação, ao confundir tecnologia e conteúdo, simbolize uma vitória da comunicação funcional.

Da mesma forma, a reflexão sobre a sociedade individualista de massas, que deve gerir a contraditória relação entre igualdade e liberdade, é questão que diz respeito tanto aos meios de comunicação de massa quanto às novas tecnologias de comunicação. As duas gerações de tecnologias da comunicação também não devem deixar de lado a questão da concepção qualitativa da recepção.

Dentre estes objetivos comuns propostos por Wolton, um ponto que não foi abordado até então é o quinto e último. Trata-se da utilização da televisão com o fim educativo de sensibilizar o grande público para as novas tecnologias da comunicação. Afinal, se a televisão é privilegiada como sendo a mediadora do mundo para grande número da pessoas, não deve estranhar que o autor proponha que ela também seja a grande mediadora do mundo multimídia. Entretanto, com isso, poderia haver uma certa perda quanto ao seu caráter de banalização do seu uso, elogiado por Wolton, vale lembrar.

Em termos das preocupações das quais os meios de comunicação de massa encontram-se quatro pontos principais. Em primeiro lugar, deveria ser afirmada a forte ambição da televisão pública na Europa, apoiada em uma igualmente ambiciosa política audiovisual. Em seguida, os meios de comunicação de massa não deveriam deixar-se levar pela idéia da supremacia da demanda em relação à oferta audiovisual, defendida pelo discurso tecnológico. A regulamentação da televisão, em nome do ideal democrático, também deve ser estabelecida, dado o impacto das novas tecnologias. E, finalmente, a televisão deveria ser valorizada em termos de qualidade na programação e por parte dos profissionais, por exemplo.

Já às novas tecnologias de comunicação caberia pensar na importância em se formular um projeto e um modelo cultural de comunicação, uma vez que tecnologia não basta para criar a comunicação. Nesse sentido, deve prevalecer a preocupação no que toca à comunicação internacional, visando à busca da intercompreensão entre os homens. A questão da regulamentação volta à tona, num alerta de que, tão importante quanto poder acessar a todo tipo de informações, é saber exatamente o que se está acessando. Por fim, deve-se contextualizar o surgimento das novas tecnologias na história dos meios de comunicação. Isso para que se possa entender melhor as razões de seu aparecimento, identificar suas forças e debilidades, além de tornar possível compará-las aos meios de comunicação de massa.

Frente a isso, Wolton esclarece que pensar na comunicação é, antes de tudo, fugir do discurso que opõe a revolução das novas tecnologias da comunicação ao arcaísmo dos meios de comunicação de massa. Para tanto, deve-se lembrar que comunicação não se reduz à tecnologia, tendo a ver com experiência da duração, com distância, com silêncio e, também, atestando os limites da interatividade.

Pesquisar sobre os serviços oferecidos pela internet e quais destes são realmente utilizados pelos usuários é outro ponto destacado pelo autor. Isso no sentido de verificar qual é a margem de manobra dos receptores das novas tecnologias de 
comunicação. Por fim, reexaminar a história das utopias em torno da comunicação no decorrer dos séculos é outra alternativa para entender a conexão entre as mesmas e as inovações tecnológicas.

\section{O deserto europeu da comunicação}

A construção de uma "comunidade internacional", tão discutida atualmente, e a relativização da "mundialização da comunicação", são os temas do último capítulo deste livro. Mais especificamente, o autor utiliza o exemplo do projeto político europeu para ilustrar o papel que a comunicação assume em termos de mediar povos diferentes e culturas diferentes ao pretender-se construir a União Européia.

Trata-se de trezentos e setenta milhões de indivíduos, de quinze países diferentes, que falam onze idiomas diferentes, os quais devem se identificar, mais efetivamente, com a União Européia. É certo que as medidas institucionais que já estão em curso, no que dizem respeito às questões econômica e política, por exemplo, aceleram esse processo. No entanto, o sucesso do projeto europeu depende da adesão dos povos ao mesmo, o que exige a tolerância mútua e a cooperação entre eles.

Nesse sentido, cabe à dimensão normativa da comunicação permitir que se ponha em prática não a superação das diferenças das culturas que estão em jogo, mas a busca pelo meio de administrá-las melhor. A comunicação, então, pode ser utilizada, simultaneamente, em termos da manutenção das identidades e no desenvolvimento de um projeto mais amplo que transcenda tais diferenças.

Como sendo o maior paradoxo da "revolução da comunicação", então, o autor francês ressalta: somente a dimensão normativa da comunicação pode relativizar os perigos de uma "mundialização da comunicação". Esta, que poderia representar um fator de desestabilização e de fragilidade das identidades pelas partes envolvidas. O capítulo de conclusão do livro, destaque no próximo item, reforça esse ponto.

\section{Concluindo}

Após resumir os tópicos do livro em dez pontos, o autor aproveita o capítulo da conclusão para destacar os últimos três itens referentes à comunicação nessa época de novas tecnologias.

O primeiro ponto faz referência à fascinação do Ocidente pelas novas tecnologias de comunicação, a ponto de acarretar o equívoco nas análises. Quanto a isso, o autor fala da confusão que há em torno do alinhamento de praticamente todas as tecnologias de comunicação até então em um único terminal de computador, por exemplo, com a pretensa equivalência de conteúdos veiculados. Nesses termos, o que importa realmente para o autor é o que permanece de diferente entre as culturas, apesar de todas as possibilidades técnicas de alinhamento.

Ainda nesse sentido, Wolton descarta a possibilidade da existência de qualquer tipo de comunicação sem que haja ruído. Seja qual for a utopia que acompanhe as tecnologias em questão. Por fim, o autor contraria a idéia de que as tecnologias de comunicação obedeçam à seguinte hierarquia: o telefone, o rádio, a televisão, o computador, os novos meios de comunicação. Na verdade, essa hierarquia refletiria a ordem cronológica de aparecimento desses meios. Na opinião do autor, o telefone e o rádio seriam os meios mais importantes entre os demais, pois fazem lembrar da importância do som e da voz para toda troca. Além disso, esses meios fariam os homens lembrarem também de que é mais importante entenderem-se do que se verem.

Feito o resumo comentado dos cinco capítulos do livro, além da sua introdução e 
conclusão, cabe que se exponha os últimos comentários.

\section{Mais alguns comentários}

Pode-se dizer que, no decorrer do livro, um ponto de destaque é o conceito de comunicação do autor, o qual deve contemplar a dimensão técnica, um projeto social e um modelo cultural dominante. Outro, é a tese de que a internet não é um meio de comunicação, por se orientar predominantemente por uma lógica da oferta, além de não se dirigir a um público definido por região, por língua ou por valores específicos. Assim, a Internet é identificada mais como um grande banco de dados e como uma grande viabilizadora de serviços do que como um meio de comunicação.

Frente a isso, o que causa estranheza é o título do livro em questão. Ou, mais especificamente, o subtítulo. Assim, a que fariam referência os "novos meios de comunicação" aos quais Wolton faz menção em "uma teoria crítica dos novos meios de comunicação"? Trata-se do papel dos meios de comunicação de massa frente ao aparecimento das novas tecnologias da comunicação? Ou à internet?

Mais uma vez, faz-se necessário - comentário a respeito de algumas contradições presentes no texto. Vale ressaltar que muitas delas poderiam ser desfeitas por meio de um cuidado maior na escolha dos termos utilizados. Com isso, certamente o debate proposto pelo autor seria enriquecido, na medida em que seriam mais facilmente identificáveis os principais tópicos tratados.

No mesmo sentido, um esforço maior em compreender que os aparecimentos dos meios de comunicação de massa e das novas tecnologias de comunicação, cada um em sua época, parecem fazer parte de um mesmo processo ampliaria o espectro de relações entre os problemas da modernidade tratados. Por exemplo, classificar a segmentação de acesso proporcionada pelas novas tecnologias de comunicação com a questão da técnica e com a ideologia de mercado e não fazê-lo quando se trata de pontuar a passagem de dois tipos de cultura para quatro tipos parece conseqüência da falta desse esforço.

Por outro lado, a dificuldade em se pensar a comunicação foi apontada por Wolton. Essa dificuldade até pode não estar relacionada com a falta de reflexão acerca da televisão, como o autor sugere, mas certamente tem relação com a dificuldade de pensar em nossa época. Enfim, torna-se possível afirmar que todo pensamento que se queira formular quanto à comunicação deve levar em conta um horizonte mais vasto, que vem a ser a questão da técnica .

\section{Referência}

WOLTON, Dominique. Internet, y después? Una teoría crítica de los nuevos medios de comunicación. Barcelona: Gedisa Editorial, 2000. 